\title{
El restaurador
}

\section{como artista-intérprete}

\author{
Carolusa González Tirado
}

N

ucho se ha discutido sobre el tipo de trabajo que desarrollamos los restauradores. Dentro y fuera del ámbito de la restauración, hay quien la considera como una labor científica porque quienes nos dedicamos a ella compartimos ciertos métodos de trabajo con las ciencias sociales y las ciencias naturales. Hay otros que la estiman como una labor más artesanal o técnica debido a que las acciones de restauración son parecidas a las que ejecutan los artesanos y los técnicos. Quisiera añadir un tercer elemento a la discusión, al comparar el trabajo del restaurador con el de cierto tipo de artistas denominados intérpretes.

Proponer este paralelismo no es un tema de discusión nuevo. Disciplinas afines a la restauración, como la arqueología y la antropología, ya han analizado la relevancia de la interpretación en su práctica profesional (Geertz 1973; Shanks y Tilley 1987). También podemos encontrar indicios sobre la relación de nuestro campo disciplinario con el quehacer artístico en el ámbito educativo. En muchas universidades de Europa la carrera de restauración está ubicada en las facultades de artes aplicadas y diseño. Incluso en España, la conservación de obras de arte está comprendida dentro de la carrera de artes plásticas. Adicionalmente, en su libro Teoría contemporánea de la restauración, Salvador Muñoz-Viñas (2003:78) propone la idea de que la restauración cumple una función expresiva y que es una actividad performativa. Sin embargo, en México hemos dejado de lado esta perspectiva: la discusión siempre se ha centrado en probar si los restauradores somos técnicos o científicos. Poco se ha explorado la parte artística de nuestro quehacer, y esto se refleja de manera directa en la formación de profesionales, particularmente en la Escuela Nacional de Conservación, Restauración y Museografía (ENCRyM) del Instituto Nacional de Antropología e Historia (INAH).

Empecemos por definir a las artes interpretativas como aquellas que presentan al público las creaciones de otros artistas; por ello, incluiremos en este grupo a los actores de teatro y cine, los bailarines, los músicos ejecutantes de algún instrumento y los cantantes.

Estaremos de acuerdo en que no es lo mismo ir a ver la ópera Elixir de amor -escrita por Gaetano Donizetti y estrenada en 1832- y escuchar Una furtiva lacrima cantada por Fernando de la Mora que por el difunto Luciano Pavarotti. Así, el artista creador es Donizetti, y a Pavarotti y De la Mora se les entrega la misma partitura, pero el resultado de la interpretación no es igual. Lo que el público recibe no es lo mismo.

En este sentido, sabemos que no es igual ver la película El resplandor, de 1980, dirigida por Stanley Kubrick, en donde aparece Jack Nicholson, que la 
serie de televisión The Shining, de 1997, dirigida por Mick Garris y protagonizada por Steven Weber. Aunque una y otra se basan en la novela homónima de Stephen King, es diferente el impacto que producen en el espectador.

Es claro que una pintura cambia después de una restauración. Baste recordar el caso de la limpieza del Juicio final, de Michelangelo, realizada bajo la dirección de Gianluigi Colalucci a principios de los años noventa del siglo pasado. Otro caso paradigmático corresponde a la Ronda nocturna, de Rembrandt, que durante su restauración, en los ochenta de la misma centuria, fue despojada de varias capas de barnices oscurecidos, y ahora recibe el nombre de Retrato de la compañía militar del capitán Frans Banning Cocq. Aunque en la práctica es imposible, sería interesante imaginar el experimento de ver cómo dos restauradores limpiarían la misma pintura: cómo se vería después de haber sido intervenida por el restaurador $\mathrm{X}$ y el restaurador $\mathrm{Y}$.

Si John Ruskin hubiese sido el encargado de dirigir la limpieza del Juicio final, tal vez hubiera indicado a los restauradores una limpieza con brocha suave, para eliminar el polvo superficial; en el hipotético caso de que la hubiese dirigido Cesare Brandi, quizás hubiera limpiado la superficie con gasolina blanca, para eliminar capas de hollín de las velas. Pero Colalucci fue más allá: no sólo eliminó las capas de hollín y los recubrimientos anteriores de gomas y colas, sino también los paños que /I Braghettone añadiera a las partes pudendas de algunos personajes, 40 años después de que la obra mural fuese finalizada por Michelangelo (Figuras 1 y 2).

\section{La importancia de la interpretación}

Las diferencias entre una pintura restaurada por fulano o por mengano pueden deberse a varias razones: la habilidad manual de cada uno de ellos; sus conocimientos técnicos y científicos, su juicio crítico, su interpretación de la obra deteriorada o su idea de cómo ésta deberá verse una vez restaurada.

Hay personas que poseen habilidades manuales sorprendentes: son capaces de manejar el hisopo, el bisturí, el pincel, como extensiones de su propia mano y, más allá, abrasionan, rascan, preparan la mezcla de color exacto y la aplican con una fina línea en el sitio preciso; son excelentes técnicos. Tal vez quienes ingresan en las instituciones de enseñanza superior en materia de restauración ya tienen desarrolladas estas capacidades y, durante sus estudios, sólo las refinan.

Por otra parte, están los conocimientos sobre materiales y técnicas de restauración, que pocos poseen antes de ingresar en la escuela y la mayoría los adquieren durante el transcurso de su formación y su carrera profesionales. El saber elegir, según las características de la obra, qué materiales y métodos aplicar en cada caso y cuáles son los posibles resultados, depende de muchas cosas: si el restaurador estudió o se formó en la práctica, cuándo estudió, qué tanto investiga, lee, se actualiza, entre otras.

Discutiremos a continuación el tercer factor que hemos mencionado: la interpretación y su relación con el jui-

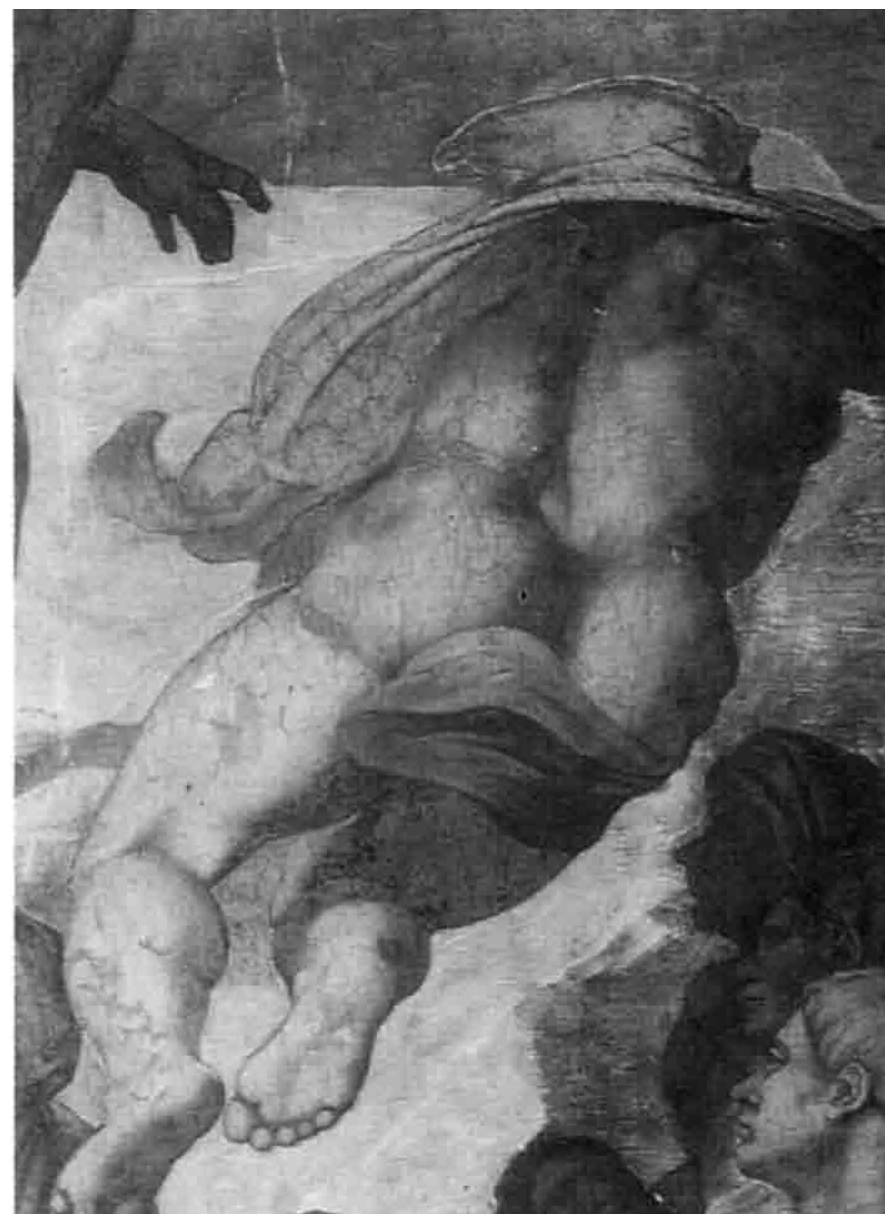

FIGURA 1. El Juicio final de Michelangelo, detalle del grupo de los elegidos en el aspecto conocido hasta los años ochenta del siglo pasado. (Fuente: Partridge, Mancinelli y Colalucci 1997).

cio crítico. En términos simples, podemos definir al juicio crítico como la correcta aplicación de la teoría de la restauración. Sin embargo, los restauradores sabemos que no es una tarea sencilla aplicar la teoría de la restauración.

Además de poseer ciertas habilidades manuales y un entrenamiento para realizar las operaciones técnicas que conlleva la restauración, el restaurador requiere ciertos conocimientos científicos que le permitan entender los resultados de los exámenes practicados al objeto con el fin de conocer sus materiales y técnicas de manufactura, así como la manera en que éstos han cambiado a través del tiempo transcurrido desde su creación. También debe contar con conocimientos de historia de la cultura material (arte y arqueología) para poder apreciar la importancia de un objeto y ubicarlo en su contexto histórico y artístico. Aunado a esto, el restaurador debe haber desarrollado las facultades críticas necesarias para apreciar los atributos estéticos de los objetos (Caple 2000:310).

El restaurador también ha de ser capaz de estudiar toda la historia del bien cultural y diferenciar, hasta donde el caso lo permita, la apariencia y la función originales de las modificaciones posteriores. Para ello, no solamente tiene que analizar los textos relevantes, sino hacer uso de sus habilidades para leer el objeto mismo y reconocer las huellas 
de su historia (Melucco Vaccaro 1996a:203). Este concepto, de leer el objeto, es lo que Jaime Cama, profesor y ex director de la ENCRYM, define como "dialogar con la obra" $y$ que muchos de nosotros hemos tardado años en entender.

Antes de preguntarse cómo restaurar, también es necesario plantear el interrogante sobre qué conservar y para quién (Melucco Vaccaro 1996a:204), cuya resolución conlleva distintos matices. Cuando se trata de una colección de cientos o miles de objetos, la respuesta puede indicar cuáles de éstos merecen una intervención de restauración, cuáles pueden sólo conservarse y cuáles pueden darse de baja del conjunto o destinarse a la investigación como ejemplares de sacrificio. Si, en cambio, se trata de un objeto único, la respuesta adquiere una gran relevancia. No basta con afirmar: se debe restaurar este objeto; sino que implica un ejercicio más complejo. Ello significa cuestionarse cuáles son las características de este objeto que deben restaurarse. En todo caso, las decisiones estarán basadas en el "gusto de cada momento o de cada persona" (Muñoz Viñas 2003:96).

Al restaurar un objeto, no sólo es importante tener en mente los principios éticos de la conservación, tales como la reversibilidad o la mínima intervención: es esencial haber establecido de antemano el fin de la restauración, esto es, qué es lo que se pretende lograr mediante el tratamiento de restauración. A este respecto, Chris Caple (2000:33) opina que la conservación puede tener tres objetivos fundamentales: revelación, investigación y preservación.

La preservación o conservación preventiva no implica ningún tipo de interpretación o juicio crítico. Simplemente, mantenemos al objeto en ciertas condiciones que garantizan que la velocidad de deterioro disminuirá de manera considerable; es decir, el objeto permanecerá durante mucho más tiempo tal como está ahora; no se quita ni se pone nada. En realidad, al hacer conservación preventiva el restaurador no contribuye en ese momento a tener un mejor entendimiento del objeto, de su significado, un mayor conocimiento del pasado. Si alguien en el futuro examina ese documento o lo restaura, tal vez podrá aportar datos o revelar ciertas cualidades del objeto, pero en el presente, el restaurador no está generando conocimientos nuevos ni alterando la manera en la que se aprecia el objeto.

La investigación aporta datos nuevos sobre el objeto, sus materiales, su técnica de manufactura, su función y su uso. Aumenta nuestro conocimiento del bien cultural en particular y del pasado en general. Actualmente existen muchas técnicas de análisis no invasivas que no alteran al objeto; incluso muchas de las que son invasivas y destructivas implican la toma de muestras tan pequeñas que las cualidades generales de la obra no se ven alteradas. En la mayoría de los casos, esta información sólo es accesible para especialistas; en algunos otros, mediante ciertos recursos museográficos, la información puede llegar al público. Por tanto, los datos generados por la investigación nos ayudan a apreciar diferentes cualidades de la obra, pero no la alteran, no le quitan ni le ponen nada, no la modifican. Tampoco implican un juicio

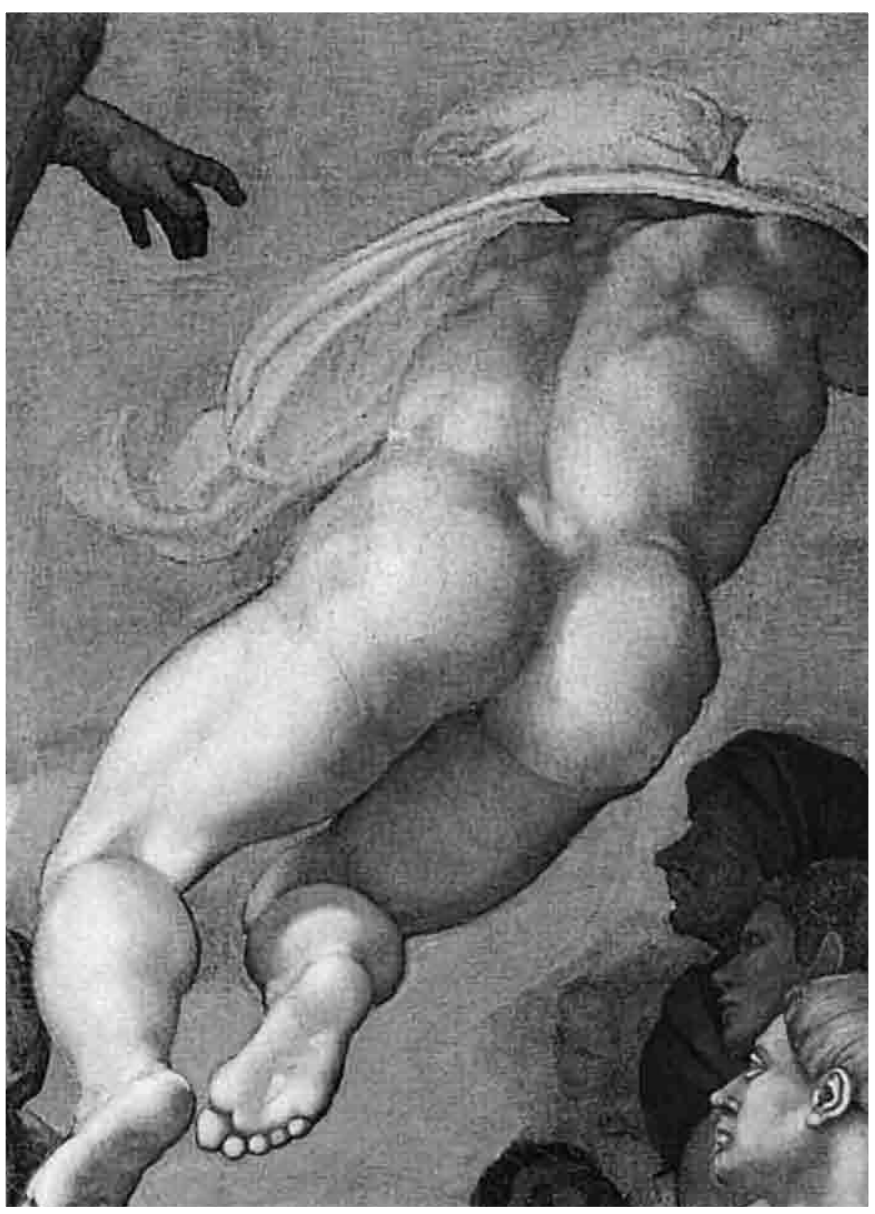

FIGURA 2. Detalle del Juicio final de Michelangelo después de su restauración por Gianluigi Colalucci a principios de los años noventa del siglo pasado. (Fuente: Partridge, Mancinelli y Colalucci 1997).

crítico ni una interpretación que modifique directamente el objeto; sin embargo, aumentan en mucho nuestro conocimiento del pasado. La selección de materiales y técnicas nos lleva a intuir intenciones de quien encarga o ejecuta la obra: en algunos casos, los materiales empleados en su manufactura son bastante tradicionales, en otras, se utilizaron combinaciones poco comunes o innovadoras. Para ciertos ejemplares se podría pensar que la selección de materiales responde al gusto personal o al capricho del autor o de quien encarga la obra. En ocasiones, el uso de materias primas y la manera de procesarlas responde a preceptos litúrgicos, reglas canónicas, usos y costumbres. El empleo de nuevos materiales o técnicas puede reflejar situaciones de más amplio alcance: el invento de un material o proceso, cambios en gustos o en la moda, influencias de otros ámbitos de la tecnología (González Tirado 2004). De manera similar, la modificaciones posteriores a la manufactura de la obra pueden responder a motivos o contextos históricos muy específicos.

Lo que Caple (2000:33) Ilama revelación -que serían las operaciones propias de restauración: limpieza, resane, reintegración-modifica directamente al objeto, le quita y le pone material, lo altera en sí, tanto en su forma y color como en su integridad. Estas operaciones implican un serio juicio crítico, una interpretación, una responsabilidad cultural. Esto no es 


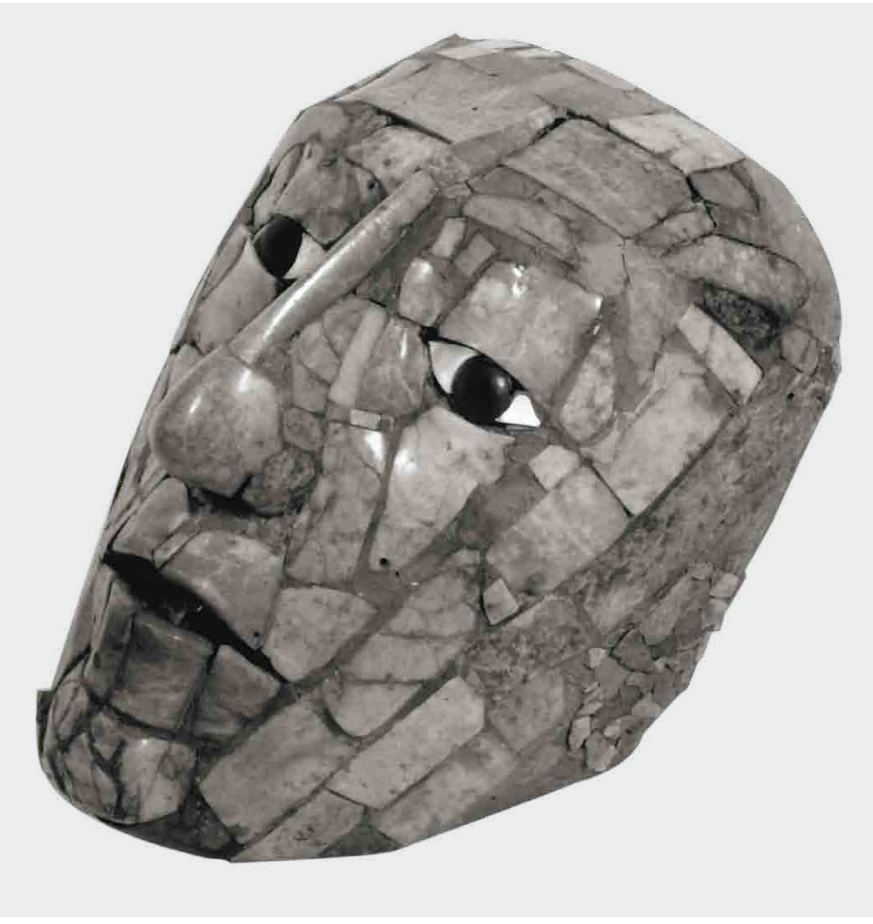

FIGURA 3. Aspecto de la Máscara de Pakal // desde su primera restauración -posteriomente a su hallazgo en 1952-, hasta el año 2000. (Cortesía de la maestra Laura Filloy Nadal, Museo Nacional de AntropologíaINAH).

nada nuevo: ya Philippot lo señaló desde los años ochenta; su amplia visión no se limita a las consideraciones técnicas, como son las recetas individuales o los métodos de tratamiento, sino que este autor aborda la esencia del problema poniendo énfasis en los temas generales en los que se apoyan las elecciones particulares (Melucco Vaccaro 1996a:204). En los últimos 20 o 30 años los restauradores nos hemos apoyado mucho en la ciencia aplicada a la arqueometría o a las pruebas de nuevos materiales para restauración, y formamos equipos interdisciplinarios con historiadores, arqueólogos, biólogos, químicos, físicos, entre otros. Sin embargo, nuestras decisiones de restauración no son científicamente objetivas, no pueden considerarse de manera absoluta y contundente como la única solución posible. Brandi, inspirado en la filosofía de Benedetto Croce, arribó a la idea fundamental de que cualquier restauración, aun la más hábil y acertada, tiene un carácter relativo, parcial y transitorio, ya que siempre estará marcada por el clima cultural en el que se ejecutó (Melucco Vaccaro, 1996a:207).

Estas dos últimas metas de la restauración, la investigación y la revelación, contribuyen de manera inmediata a nuestro conocimiento del pasado, a nuestra apreciación del objeto (Caple 2000:34-35).

Existen ejemplos de obras que se han desfigurado mediante procesos de restauración. Esto podría atribuirse a la poca habilidad manual de quien ejecuta la restauración o a una mala selección de los materiales y técnicas empleadas para la restauración. Pero en muchas ocasiones el problema es de interpretación: si el restaurador no entiende el objeto que tiene en sus manos, si no es capaz de apreciar sus cualidades particulares, es imposible que pueda dirigir las acciones de restauración hacia la recuperación de sus cualidades intrínsecas. Es como ponerse a caminar sin saber a qué punto se quiere llegar. Así, una mala restauración distorsionará la apreciación que se tenga del objeto y, por ende, la manera en la que se conciba el pasado. El ejercicio de la restauración implica, por lo tanto, una fuerte responsabilidad cultural.

Un ejemplo muy claro de esto es la Máscara de Pakal II descubierta en la Tumba del Templo de la Inscripciones, en la Zona Arqueológica de Palenque, Chiapas, en 1952. Posteriormente a su hallazgo, este objeto se restauró de tal manera que representaba al rostro de un personaje hinchado y deformado (Figura 3).

Durante casi 50 años, este aspecto determinó la forma en que se vio y se apreció el retrato de un glorioso gobernante maya. En el año 2000 se iniciaron los estudios de este mosaico de piedra verde que culminaron en la obra restaurada en 2003 (Laura Filloy Nadal, comunicación personal 2009) (Figura 4).

Gracias al ejercicio de investigación llevado durante esta última intervención se determinó que en los años cincuenta hubo ciertos problemas en la elección de los materiales empleados para unir y montar la máscara. No obstante, el principal error detectado fue de interpretación. Aunque los adhesivos y las pastas utilizados en la década de 1950 para armar la máscara hubieran sido los que ahora se consideran más adecuados y la habilidad manual de quien armó la máscara hubiese sido extraordinaria, si la obra se hubiera interpretado de la manera correcta, el resultado de la restauración no habría sido tan desastroso. En síntesis, una mala interpretación del objeto es tan nociva como una mala selección de materiales y técnicas o una deficiente habilidad manual del restaurador.

Otro caso que ilustra el problema de la interpretación es el de una escultura helenística, Laocoön, descubierta en el siglo XVI con notables faltantes en los brazos de la figura antropomorfa central. La restauración más antigua que se conoce, datada para el siglo XVI, completó dichos faltantes de acuerdo con cánones artísticos de la época (Figura 5).

Durante siglos, la obra fue conocida con esa imagen. A principios del siglo XIX, se encontró el brazo original de Laocoön, el cual fue reintegrado en su lugar, eliminando los agregados anteriores, durante la restauración realizada entre 1957 y 1960 (Figura 6).

Al margen de la época en la que se hizo cada una de las intervenciones, y enfocándonos solamente en el resultado final, es evidente que la escultura tiene notables diferencias y que el impacto que produce en el espectador es diferente (Philippot 1996:22-22).

Este caso nos puede llevar a discutir, como lo discutieron los restauradores que intervinieron esta obra, la pertinencia de eliminar intervenciones anteriores y cambiar así la manera en que se la conoce. Esto se puede resumir señalando que se decidió eliminar la interpretación manierista de una escultura clásica, lo que Brandi (1971:12) definiría 
como la segunda historicidad de la obra, cuyo impacto en la conciencia humana se mantuvo durante siglos, para darle preferencia a la interpretación moderna (segunda mitad del siglo $\mathrm{xx}$ ), que intenta recuperar la intención original de quienes esculpieron la obra. Mi objetivo no es juzgar cuál de estas interpretaciones es mejor o más correcta, más válida o respetuosa, sino sólo señalar que la percepción de la obra es diferente.

\section{La enseñanza de la interpretación en restauración}

Si consideramos que la interpretación de un objeto (Ilámese obra de arte o bien cultural) es un paso fundamental previo a la decisión de los tratamientos de restauración que se han de ejecutar, entonces es evidente que un restaurador debe saber interpretar el objeto que tiene en sus manos para poder realizar una buena restauración. ¿Cómo y en qué momento aprende a interpretar un objeto que se ha de restaurar? Por ello, en el transcurso de los estudios profesionales en restauración se debe enseñar a los alumnos a interpretar los objetos motivo de su intervención.

Sin embargo, tomando como ejemplo los objetivos de la Licenciatura en Restauración de la ENCRyM no se prevé específicamente este punto. Tampoco se lo menciona en la estructura del plan de estudios ni en el perfil de egreso ni en la descripción del eje teórico metodológico. Pareciera que la noción de la interpretación se sugiere sólo con frases como "respeto a los bienes culturales tangibles y su devenir en el tiempo", "manera responsable de ejercer la profesión", "apego a criterios teóricos", "el sentido ético", "actitudes para aplicar criterios", etcétera.

En otras licenciaturas que forman intérpretes, como sería el caso de los músicos instrumentistas, no existe una asignatura específica de interpretación. Éstos la aprenden con su profesor de instrumento. Y la manera en la cual un profesor enseña a sus alumnos a interpretar la música tampoco está sistematizada; cada profesor enseña a su manera (Claudia Herrerías Guerra, comunicación personal 2009). Entonces, en el caso de los músicos, la calidad de interpretación que puede esperarse de cierto individuo no depende únicamente de su grado académico ni de sus conocimientos y habilidades técnicas, sino, en mucho, de las personas que intervinieron en su formación. Por esta razón, sus currículos adquieren la siguiente forma:

Atanacio Enríquez. Estudió la Licenciatura Instrumentista en Guitarra bajo la cátedra del distinguido maestro Juan Carlos Laguna. Su formación se ha fortalecido a través de distintas participaciones en diversos festivales y clases magistrales con reconocidos ejecutantes de la guitarra, entre los cuales destacan: Joaquín Clerch, de Cuba; Martha Master y Jason Vieux, de Estados Unidos; Francisco Gil y Pablo Garibay, de México; Denis Azabagic, de Bosnia; Adriano del Sal, de Italia; Eduardo Garrido, de España, y Eduardo Isaac, de Argentina.

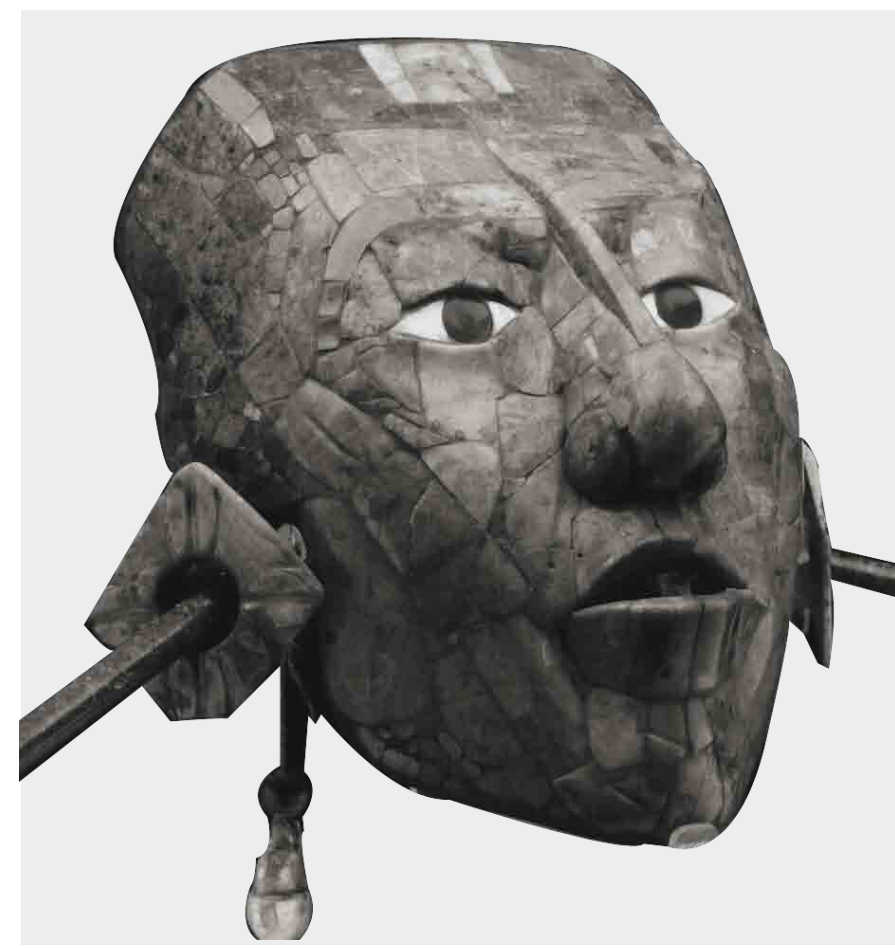

FIGURA 4. Apariencia de la Máscara de Pakal II, una vez culminada su intervención en 2003. (Cortesía de la maestra Laura Filloy Nadal, Museo Nacional de Antropología, INAH).

En la Licenciatura en Restauración de la ENCRyM no existe una asignatura específica en la cual se enseñe al alumno un método para interpretar obras. Éste aprende a hacerlo dentro de los seminarios-talleres, cuyos programas no describen la manera en que esto se enseña. La experiencia indica que durante su estadía en dichos seminarios-talleres, los alumnos interpretan los objetos que restauran, ya sea antes, durante o después de la intervención. Al revisar las ponencias presentadas en el Foro Académico 2008 de la ENCRYM se puede constatar el aprendizaje. Sin embargo, pareciera que la interpretación no es homogénea, que varía en calidad y nivel de profundidad. Estas variaciones podrían atribuirse a diferentes factores: los conocimientos y aptitudes personales de cada alumno, las características del objeto que se ha de restaurar, el seminario-taller en el cual se realizó el trabajo, el o los profesores que participaron en él en un semestre dado.

Pareciera entonces que el caso de los restauradores es similar al de los músicos; que, en buena medida, uno aprende a interpretar con su profesor de taller. Así, la calidad de interpretación de un restaurador no depende solamente del programa de estudio ni de sus conocimientos y habilidades, sino de las personas que participaron en su formación. Tal vez yo debería cambiar la estructura de mi currículum y escribir:

Carolusa González Tirado. Licenciada en Restauración de Bienes Muebles. Estudió restauración de cerámica con Luciano Cedillo y Luz de Lourdes Herbert; mural, con Martha Tapia y Sergio Montero; caballete, con Liliana Giorguli, etc. 


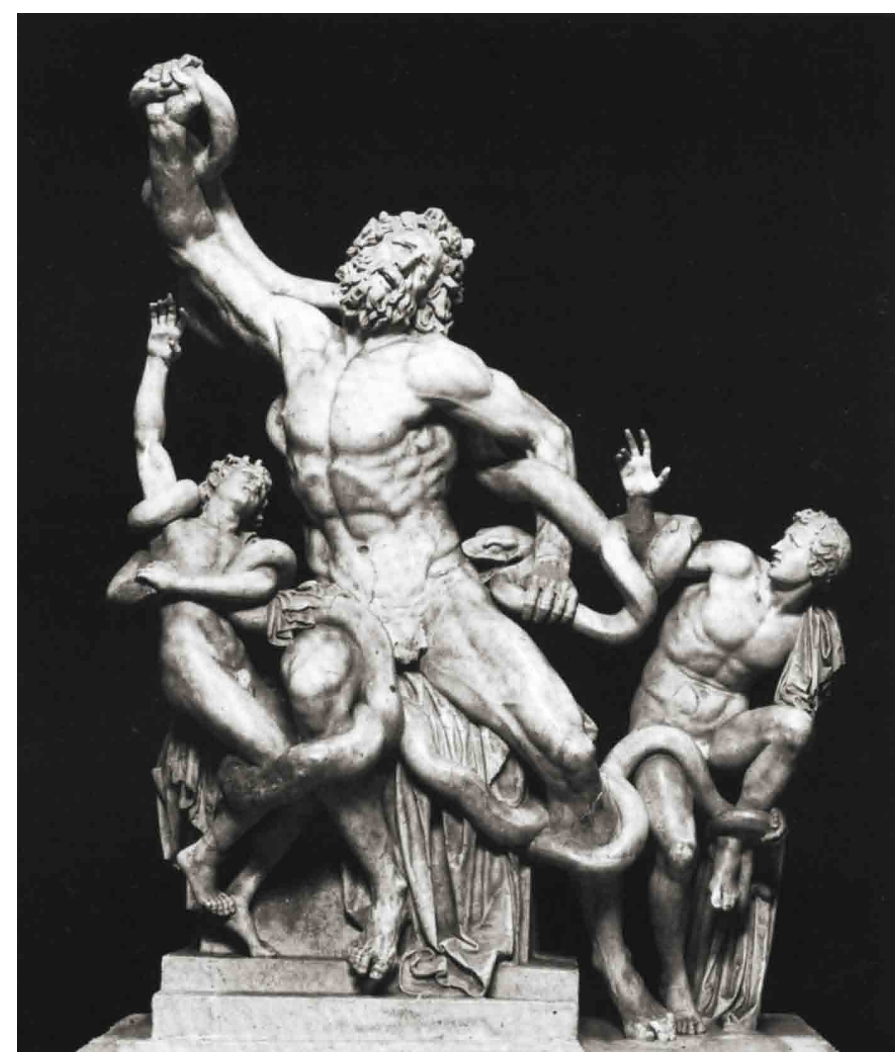

FIGURA 5. El Laocoön, obra ejecutada por Agesandro, Polidoro y Atenodoro de Rodas, con la intervención realizada en el siglo XVI. (Fuente: Philippot 1996:220)

Quien lea estas líneas sabrá que mi manera de interpretar un objeto es muy distinta de alguien que estudió con otros profesores.

\section{La responsabilidad cultural del restaurador}

Sin embargo, y para terminar, debo recalcar una gran diferencia entre los restauradores y otros artistas-intérpretes. Si compro un disco de Fernando de la Mora y no me gusta cómo interpreta Una furtiva lacrima, puedo tirar ese CD a la basura, ir a la tienda y comprarme un disco que contenga la misma aria interpretada por Luciano Pavarotti, que me gusta más. Puedo ver la película El nombre de la rosa, dirigida por Arnaud, comprar la traducción al español de la novela o adquirir el texto en italiano y leerlo. Pero, si voy a la Capilla sixtina y no me gusta la restauración de Colalucci... no puedo ir a otra Capilla sixtina a ver la interpretación que otro restaurador hizo sobre el Juicio final, ni viajar en el tiempo y ver la pintura original de Michelangelo.

Con esto quiero subrayar la gran responsabilidad cultural que implica cualquier proceso de restauración. En el caso de las artes escénicas, la obra original permanece sin alteración y puede ser interpretada por otra persona en cualquier momento. Comparativamente, la restauración modifica -en mayor o menor grado y dependiendo del caso en particular- el bien cultural objeto de su intervención. Aquellas operaciones de restauración que implican agregar algo nuevo a la obra, como son: la unión de fragmentos, la reposición de faltantes, la reintegración, la aplicación de barnices o capas de protección, pueden ser consideradas reversibles $y$, en este sentido, dejan abierta la posibilidad de nuevas interpretaciones. Sin embargo, las operaciones que implican remover material, como es el caso de la limpieza, son absolutamente irreversibles.

La relevancia de las operaciones de limpieza ha sido reconocida, y por esta razón el concepto de pátina ha adquirido importancia al discutir cuestiones sobre la teoría de la restauración.

Hay restauradores que aparentemente prefieren dejar los objetos sin limpiar, ya sea para evitar la pérdida irreparable de restos de acabados superficiales, por considerar que estaremos más en contacto con la mente del artista al dejar la obra con su pátina (Brandi 1949), o bien porque se cree que las huellas del uso y del envejecimiento se alteran severamente durante la restauración; pero aun cuando respeten de manera consciente dichas huellas, el resultado puede ser un efecto inadecuado. Como lo indica Van de Wetering (1996:417), la superficie puede adquirir una apariencia que no existe en la naturaleza. Por ello, creo que algunos de los materiales que se han formado o depositado en la superficie del objeto deben eliminarse. Sin embargo, esta limpieza debe ser selectiva.

La razón de ello es que al eliminar toda la suciedad y todos los productos de alteración de un objeto antiguo, le estamos dando la apariencia de nuevo, lo cual crea una contradicción histórica: una discordancia dentro del mismo objeto respecto de su paso en el tiempo, lo que constituye un tipo de falsificación (Philippot 1966:141). Es como si una persona de raza negra tuviera piel clara y nariz respingada. El resultado sería una especie de máscara o momia que ya no tiene una expresión natural de persona. Lo mismo sucede con los objetos: uno mal restaurado pierde su expresión de objeto antiguo, creado por cierta persona en cierta época, que ha sobrevivido años o siglos y ha ido cambiando con el tiempo; queda convertido en un objeto estilizado de nuestra propia época (Van de Wetering 1996:419).

Creo que, para evitar caer en este extremo, tanto Cesare Brandi como Ernst van de Wetering prefieren no realizar ningún proceso de limpieza. En este sentido, coincido con ellos: si una obra no se restaura, si no se le hace ningún tratamiento de limpieza, seguirá deteriorándose poco a poco, y tal vez acabe de destruirse en 20, 50, 100 o 200 años. Sin embargo, durante este tiempo la obra seguirá conteniendo toda la información que posee. Otras personas podrán estudiar sus diferentes aspectos y tal vez dentro de algunos años alguien realice un tratamiento de restauración más adecuado para este objeto en particular. Comparativamente, si la obra se somete a una restauración inadecuada, en pocas horas perderemos mucha información que ya nadie podrá estudiar nunca; es más, es probable que ni siquiera nos demos cuenta de cuánta información estemos perdiendo. Muchas veces estos tratamientos erróneos acortan muchísimo la vida de la obra; al eliminar la pátina protectora, podemos 


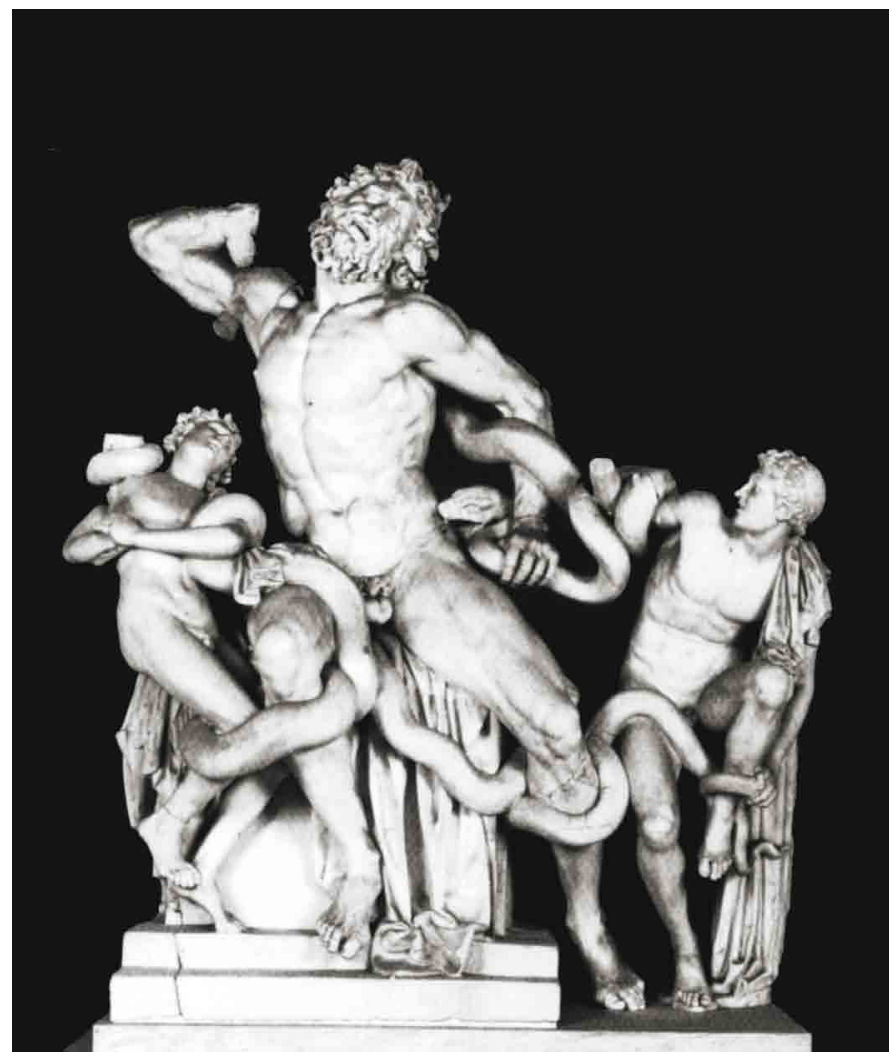

FIGURA 6. El Laocoön con la reintegración de su brazo original. (Fuente: Philippot 1996:221).

reducir su tiempo de vida a la mitad, o a una cuarta parte, de la expectativa original. Además, sin importar si dura 20, 50 o 100 años, se debe considerar que una obra mal restaurada transmite información distorsionada. En vez de contribuir a nuestro conocimiento del pasado, la intervención contribuye a nuestra confusión.

Para que un restaurador decida qué tratamiento de limpieza utilizar en un caso específico, debe definir previamente cuál es el nivel de limpieza deseable en ese objeto; es decir, se debe determinar cuál deberá ser su aspecto después de la limpieza. De acuerdo con los lineamientos teóricos y éticos que guían la práctica de la restauración, se debe eliminar toda la suciedad y los productos de alteración que desfiguran la apariencia del objeto, y en la superficie deberá quedar únicamente su pátina. Ésta, señala Paul Philippot (1973:9), está constituida por las alteraciones físico-químicas de los materiales originales, las cuales son inevitables y generalmente irreversibles, e indica que:

cuando estas alteraciones son consideradas como distorsiones del valor formal del objeto y ya no un acrecentamiento de su calidad estética, el objeto no puede ser definido objetivamente $y$, por lo tanto, se transforma nuevamente en materia de interpretación crítica y responsabilidad cultural.

Es necesario definir, entonces, para cada caso, cuál es la pátina de ese objeto en particular para poder distinguir entre ésta y el material que debe eliminarse. Ese aspecto de la superficie, que porta las huellas del tiempo al que el objeto ha sobrevivido, se define mediante un término a la vez ambiguo y complejo: la pátina. Esta dificultad fue detectada ya desde hace más de 40 años por el propio Philippot (1966:139), al escribir que ésta no es un concepto físico o químico, sino crítico. Es la combinación de las alteraciones normales que afectan la apariencia de un objeto sin desfigurarlo. Restaurar, según esta noción de normalidad, no niega el concepto de pátina: tan sólo revela que no concierne al material, sino que surge del ámbito de la crítica y siempre implica un juicio estético (Philippot 1966:139). Al momento de evaluar cada caso para decidir hasta qué grado debe llegar la limpieza de una obra, es necesario incluir criterios estéticos e históricos para evitar caer en la subjetividad del gusto personal. Indudablemente, éste sería el caso cada vez que un restaurador evade el problema crítico porque no lo tomó en cuenta. Entonces, la objetividad de la restauración es ilusoria al emplear un criterio material, en vez de un juicio crítico. En general, la apreciación de la pátina se funda en una comparación mental entre la apariencia actual del objeto - o de las diferentes apariencias que podría tener según el grado de limpieza- con la idea de cómo se imagina que debió haber sido su apariencia original (Philippot 1966:139).

Nuestro juicio debe fundarse en evidencia objetiva:

- Datos históricos, en particular historia del arte e historia de la tecnología.

- Datos sobre los materiales presentes en el objeto que se ha de restaurar.

Tampoco debemos olvidar que muchos objetos han sido intervenidos en el pasado. Es necesario conocer los objetivos de las intervenciones, así como los materiales y métodos utilizados con mayor frecuencia por los restauradores o reparadores de diferentes épocas y escuelas, para poder explicar ciertas alteraciones en los objetos. A lo largo de la historia ha habido reparaciones que tendieron a limpiar lo que se consideraba mugre, mientras que otras intervenciones han buscado tapar o repintar esa suciedad. Toda esta información es necesaria para evaluar las alteraciones que presente la superficie de un objeto, y decidir si son una pátina o un daño que desfigura al objeto.

\section{Conclusiones}

El restaurador deberá asumirse, de manera consciente e intencionada, como un artista-intérprete, en el entendido de que la manera en que él interprete la obra que se ha de restaurar determinará la forma y el grado en el que el público la apreciará. O bien asumirse como un crítico de arte, cuya interpretación de la obra que será restaurada definirá la apreciación que el público podrá tener de ella. Es indispensable que el restaurador asuma de manera consciente su responsabilidad cultural para evitar caer en subjetividades de apreciación personal o en la aplicación indiscriminada de recursos de restauración. 
Creo que hasta el momento, los restauradores mexicanos no hemos asumido de manera cabal nuestra responsabilidad como intérpretes. No somos conscientes de la manera en que enseñamos esta habilidad a los restauradores en formación. Negamos la posibilidad de que nuestras operaciones de restauración estén basadas en los gustos personales o grupales.

En la mayoría de los casos, las intervenciones de restauración se justifican utilizando ciertas frases como escudos protectores: "se emplearon materiales cuya estabilidad ha sido probada", "se realizó una limpieza respetando la pátina", "se reintegró usando un tono neutro", etc. Pero rara vez se explica por qué, entre diferentes estados posibles de la obra después de la restauración, se optó por uno de ellos.

Cuando yo abro mi ejemplar de la novela de Umberto Eco, El nombre de la rosa, fácilmente puedo encontrar el nombre del traductor, si veo el cartel de la película basada en el mismo libro, aparecen los nombres del director y los actores. Cuando voy a un museo y veo una obra, la cédula no incluye datos que indiquen si la obra está restaurada o no, quién la restauró, cuándo se restauró. ¿Es por modestia del restaurador? $i$ Es por que no se quiere asumir la responsabilidad del estado actual de la obra? ¿Es por que queremos que el público crea que ésa es la apariencia de la obra recién creada por el autor?

\section{Referencias}

Brandi, Cesare

1949 "The Cleaning of Pictures in Relation to Patina, Varnish and Glazes", Burlington Magazine 91 (556): 183-89.

1971 Principios de la teoría de la restauración, México, UNAM.

Caple, Chris

2000 Conservation Skills: Judgment, Method and Decision Making, Londres, Routledge.

Cimadevilla Cervera, Ilse y Carolusa González Tirado

1996 "La teoría de la restauración aplicada en la intervención de objetos metálicos", Imprimatura. Revista de Restauración 12: 25-33.

Geertz, Clifford

1973 The Interpretation of Cultures, Nueva York, Basic Books.

González Tirado, Carolusa

1997 "Importancia de la selección de los métodos de limpieza para metales arqueológicos", Correo del Restaurador 4, documento electrónico disponible en http://www.conservacionyrestauracion.inah.gob.mx/html/Publindice.html, consultado en noviembre de 2009.
2004 "La miniatura como objeto integral: materiales y técnicas", en Santuarios de lo íntimo, retratos en miniatura y relicarios, la colección del Museo Soumaya, 38-61, México, Carso.

Melucco Vaccaro, Alessandra

1996a "Introduction to Part III: The Emergence of Modern Conservation Theory", en Nicholas Stanley-Price, M. Kirby Talley Jr. y Alessandra Melucco Vaccaro (eds.), Historical and Philosophical Issues in the Conservation of Cultural Heritage, Los Ángeles, The Getty Conservation Institute, 202-211.

1996b "Introduction to Part VII: The Idea of Patina", en Nicholas Stanley-Price, M. Kirby Talley Jr. y Alessandra Melucco Vaccaro (eds.), Historical and Philosophical Issues in the Conservation of Cultural Heritage, Los Ángeles, The Getty Conservation Institute, 366-371.

Muñoz Viñas, Salvador

2003 Teoría contemporánea de la restauración, Madrid, Síntesis.

Partridge, Loren, Fabrizio Mancinelli y Gianluigi Colalucci 1997 El Juicio Final: la obra y su restauración, Madrid, Nerea.

Philippot, Paul.

1966 "La notion de patine et le nettoyage des peintures", Bulletin de I'Institute Royal du Patrimoine Artistique 9: 138-146.

1973 Restauración: filosofía, criterios, pautas. Documentos de trabajo del Primer Seminario Regional Latinoamericano de Conservación y Restauración, México, INAH-ICCROM.

1996 "Restoration from the Perspective of the Humanities", en Nicholas Stanley-Price, M. Kirby Talley Jr. y Alessandra Melucco Vaccaro (eds.), Historical and Philosophical Issues in the Conservation of Cultural Heritage, Los Ángeles, The Getty Conservation Institute, 216-229.

Shanks, Michael y Christopher Tilley

1987 Reconstructing Archaeology: Theory and Practice, Londres, Routledge.

Van de Wetering, Ernst

1996 "The Surface of Objects and Museum Style", en Nicholas Stanley-Price, M. Kirby Talley Jr. y Alessandra Melucco Vaccaro (eds.), Historical and Philosophical Issues in the Conservation of Cultural Heritage, Los Ángeles, The Getty Conservation Institute, 415-421.

Weil, Phoebe Dent

1976 "A Review of the History and Practice of Patination", Proceedings of a Seminar on Corrosion and Metal Artifacts: A Dialogue between Conservators and Archaeologists and Corrosion Scientists held at the National Bureau of Standards, Gaithersburg, National Bureau of Standards, 77-92. 


\section{Resumen}

Este texto propone comparar el trabajo del restaurador con el de los artistas-intérpretes, en el sentido de que presentan al público las creaciones de otros artistas. Subraya la diferencia entre la habilidad manual, los conocimientos científicos y tecnológicos, en relación con la capacidad y sensibilidad necesarias para la interpretación de un objeto durante su restauración. Mediante ejemplos, se enfatiza la gran responsabilidad cultural que tiene el restaurador al interpretar el mensaje que deberá transmitir el objeto restaurado, cuestionando la enseñanza de la interpretación en los estudios profesionales en materia de restauración y sus implicaciones curriculares. El análisis abunda en las operaciones de limpieza, para discutir el concepto de pátina. Para concluir, este artículo se apoya en la idea de que la restauración no puede juzgarse como científicamente objetiva ni técnicamente adecuada, haciendo evidente la subjetividad que implica cualquier proceso de interpretación: un tema, que sin la menor duda, no se ha abordado de manera consciente y responsable en México.

\section{Palabras clave}

Teoría de la conservación, subjetividad, restauración, interpretación, profesional.

\section{Abstract}

Conservation work is compared to that carried out by performing artists, since they both deliver to an audience the interpretation of the work by other artists. It emphasizes on the difference between hand skills, scientific and technological knowledge, in relation to the sensitivity and ability required for the interpretation of an object during its conservation. Through examples, it highlights the enormous cultural responsibility of the conservator through the interpretation of the message that the restored object should communicate, questioning the teaching of interpretation skills in professional conservation training, as well as its curricular implications. Cleaning operations are used as an illustrative example, in order to discuss the concept of patina. This article concludes that conservation cannot only be judged as scientifically objective or technically skilled since it is obvious that any interpretation implies subjectivity: a topic that surely has not been consciously and responsibly examined in Mexico.

Keywords

Conservation theory, Subjectivity, Restoration, Interpretation, Professional. 